\title{
Endodontic re-treatment and restorative treatment of a dens invaginatus type II through new technologies
}

\author{
Álvaro Zubizarreta-Macho ${ }^{1}$, Alberto Ferreiroa ${ }^{2}$, Rubén Agustín-Panadero ${ }^{3}$, Cristina Rico-Romano ${ }^{1}$, \\ Ana-Belén Lobo-Galindo ${ }^{4}$, Jesús Mena-Álvarez ${ }^{5}$
}

${ }^{1}$ DDS, PhD. Associate professor. Department of Endodontics. Faculty of Health Sciences. Alfonso X el Sabio University. Madrid. Spain

${ }^{2}$ DDS, PhD. Associate professor. Department of Dental Prosthesis. Faculty of Dentistry. Complutense University. Madrid. Spain

${ }^{3}$ DDS, PhD.Adjunct Professor. Department of Dental Medicine. Faculty of Medicine and Dentistry. University of Valencia. Spain ${ }^{4}$ DDS, MS. Associate professor. Department of Endodontics. Faculty of Health Sciences. Alfonso X el Sabio University. Madrid. Spain

${ }^{5}$ DDS, PhD. Head Director. Department of Endodontics. Faculty of Health Sciences. Alfonso X el Sabio University. Madrid. Spain

Correspondence:

Faculty of Medicine and Dentistry

(Unit of Prosthodontics and Occlusion)

University of Valencia, Spain

C/ Gascó Oliag, 1. 46021 Valencia

ruben.agustin@uv.es

Zubizarreta-Macho A, Ferreiroa A, Agustín-Panadero R, Rico-Romano C, Lobo-Galindo AB, Mena-Álvarez J. Endodontic re-treatment and restorative treatment of a dens invaginatus type II through new technologies. J Clin Exp Dent. 2019;11(6):e570-6.

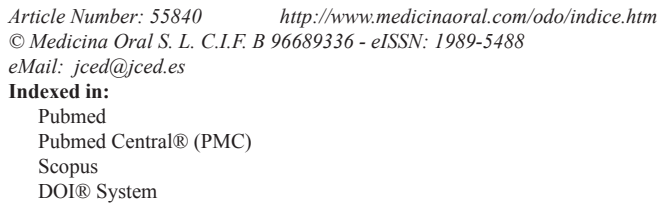

\begin{abstract}
Background: The complex anatomy of dens invaginatus makes access cavity to root canal system difficult, which has an impact on the prognosis of these teeth. A novel technique, based on new technologies, is proposed to make access cavity conservative and guided with minimal dental structure lost.

Material and Methods: This case report shows the root canal retreatment and the endodontic surgery of a dens invaginatus type II in a left lateral upper incisor previously treated which was affected by a chronic apical abscess and an apical fracture. A Cone Beam Computed Tomography was performed to better diagnosis the dental anatomy. An intraoral scan was performed to get a digital 3D model. A computer-guided implant planning software was used to plan the access cavity and design the splint guided. Finally, the clinical crown was restored by a resin nanoceramic veneer made by a chairside system made up of an intraoral scanning unit and a grinding unit. Last, the authors carried through the endodontic surgery to extract the apical fractured fragment.

Results: Follow-up appointments at 6,12 and 18 months showed a radiographic reduction of the periapical lesion and absence of clinical signs.

Conclusions: The splint guide allowed a guided and conservative access cavity to root canal system. It facilitates the root canal retreatment and improves the prognosis of the teeth with dental malformations.
\end{abstract}

Key words: CAD-CAM, Cone-Beam Computed Tomography, dens in dente, dens invaginatus, dental pulp cavity, endodontics. 


\section{Introduction}

Dens invaginatus (DI) is defined as a dental malformation with a variable prevalence range from $0.04 \%$ to $10 \%$ (1). Hülsmann M. describes its etiology as an invagination of the enamel organ into the dental papilla during the process of odontogenesis (DI coronalis) $(2,3)$. Some authors focus the source of the etiology as an infolding of Hertwig's epithelial root sheath into the developing root (DI radicularis). The result of this malformation is the most severe alteration and receives the following meanings: dens in dente, invaginated odontoma, dilated gestant odontoma, dilated composite odontoma, tooth inclusion and dentoid in dente (3-5).

This anatomic disorder is classified into three categories according to the degree of malformation, and its relation to the periodontal ligament (PDL): Type I: the invagination ends as a blind sac, confined to the crown $(65,9 \%)$. Type II: the invagination extends apically beyond the external cementoenamel junction (CEJ), ending as a blind sac confined to the crown of the tooth $(29,5 \%)$. Type III: the invagination extends beyond the CEJ ending in the lateral (III a) or apical (III b) foramen $(4,6 \%)$. The pulp tissue presents in the DI, is rarely directly correlated to the main root of the canal $(3,5)$.

The teeth most affected by this anatomical alteration are the maxillary lateral incisors (9\%) that can present a bilateral occurrence of $43 \%(3,5-7)$.

Cone-beam computed tomography (CBCT) is considered an essential tool for the diagnosis, treatment planning and follow-up appointments of teeth affected by anatomical malformations (8-10). Moreover, the digital file obtained with CBCT can be combined with other digital files obtained from other devices, as for example extraoral scanner or digital, for to integrate the information for manufacturing splint guides for different treatments, even in the field of endodontics. In addition, to restore the tooth treated endodontically, it is possible to do chairside digital workflow, through of intraoral digital scanner and milling unit. Within of this chairside workflow, it is possible to do a the restoration with a total chairside workflow, where the clinician to design and to fabricate the restoration in the clinic or partial chairside workflow, where an expertise lab technician receive the standard triangulation language (STL) file, via internet and to design the restoration and to sent the STL file of desing to the clinic for manufacturing. Within of this chairside workflow, it is possible to do a the restoration with a total chairside workflow, where the clinician to design and to fabricate the restoration in the clinic or partial chairside workflow, where an expertise lab technician receive the standard triangulation language (STL) file, via internet and to design the restoration, and after to sent the STL file of the design of the restoration, to the clinic for manufacturing.

The complex and variable anatomy from DI influen- ces over the treatment planning, making unpredictable conventional therapeutic procedures such as: preventive treatments $(1,3,8)$, nonsurgical root canal therapy $(4,11)$, endodontic surgery $(12,13)$, pulp revascularization (1416), intentional replantation, extraction (17), or a combination of these (1-3). The management of traumatized teeth with a chronic apical abscess associated to fractured apex requires a multidisciplinary approach with endodontic surgery as an adjunct of root canal therapy in order to promote bone healing (18).

Conventional location of root canal system of DI results difficult, and has the risk to cause perforations, fractures or weak the tooth. Furthermore, the complex and irregular anatomy of DI make any canal susceptible of being omitted, leading to endodontic treatment failure (19). Therefore, is important to consider an access cavity procedure able to locate all canals without removing excess tooth structure. The purpose of this case report was to show an innovative technique to allow a guided and conservative access cavity to the root canal system of a DI type II, preserving dental tissue as much as possible and making the therapeutic prognosis more predictable.

\section{Case Report}

A 28-year-old female patient was referred to the department of Endodontics of the Alfonso X el Sabio University, for diagnosis and management of a chronic apical abscess on a previously treated tooth, secondary to a traumatism on left upper lateral incisor (20) (Fig. 1A). A CBCT (WhiteFox, Acteón Médico-Dental Ibérica S.A.U.-Satelec, Merignac, France) was taken to better diagnosis the complexity of the DI Oehlers type II and the fractured apex, based on the following exposure parameters: 105,0 kilovolt peak, 8,0 milliamperes, 7,20 seconds, and a field of view of $15 \times 13$ millimeters (Fig. 2A). The anatomical complexity of root canal system, justified the need to request a splint that would guide the access cavities. The design of the splints was assisted by means of a computer-guided implant planning software (SimPlant ${ }^{\circledR}$, Dentsply Implants, Hasselt, Belgium). A 3D printer (ProJet ${ }^{\circledR}$ 6000. 3D Systems $@$, Rock Hill, SC, USA) was used to fabricate the splints from stereolithography resin, with the exception of the stainless steel cylinder used to guide the access cavities to root canal system (Fig. 3). The length and the diameter of the guiding cylinders were $5 \mathrm{~mm}$ y $1,3 \mathrm{~mm}$, respectively. A diamond burr surface was selected with a diameter of 1,2 $\mathrm{mm}$ on the active part, and a total length $14 \mathrm{~mm}$ (Ref.: 882314 012, Komet Medical, Lemgo, Germany).

Root canal retreatment was performed, after applying infiltrative anesthesia (Artinibsa, Inibsa S.A., Lliça de Vall, Barcelona, Spain) and rubber dam for absolute isolation (Hygenic ${ }^{\circledR}$ dental dam, Coltene ${ }^{\circledR}$ Whaldent Gruppe, Altstätten, Switzerland). The access cavities were made by means of the splint guide (Fig. 3), and the 


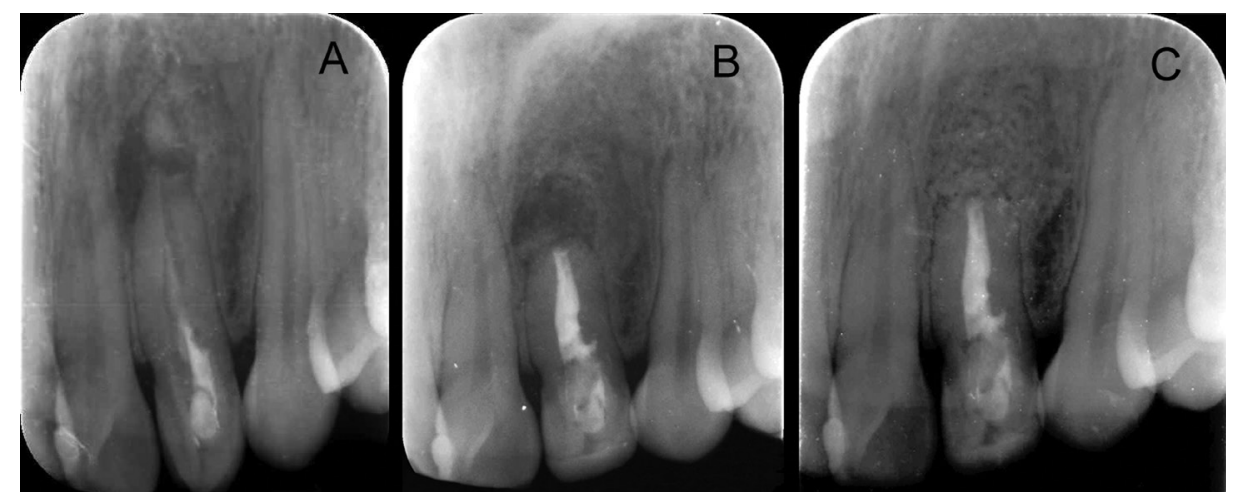

Fig. 1: Preoperative periapical radiograph of tooth 2.2 showing previous endodontic treatment and the apical fracture (arrow) (A), post-surgery periapical radiography (B) and check periapical radiography followup at 18 months after treatment. Complete periradicular healing $(\mathrm{C})$.

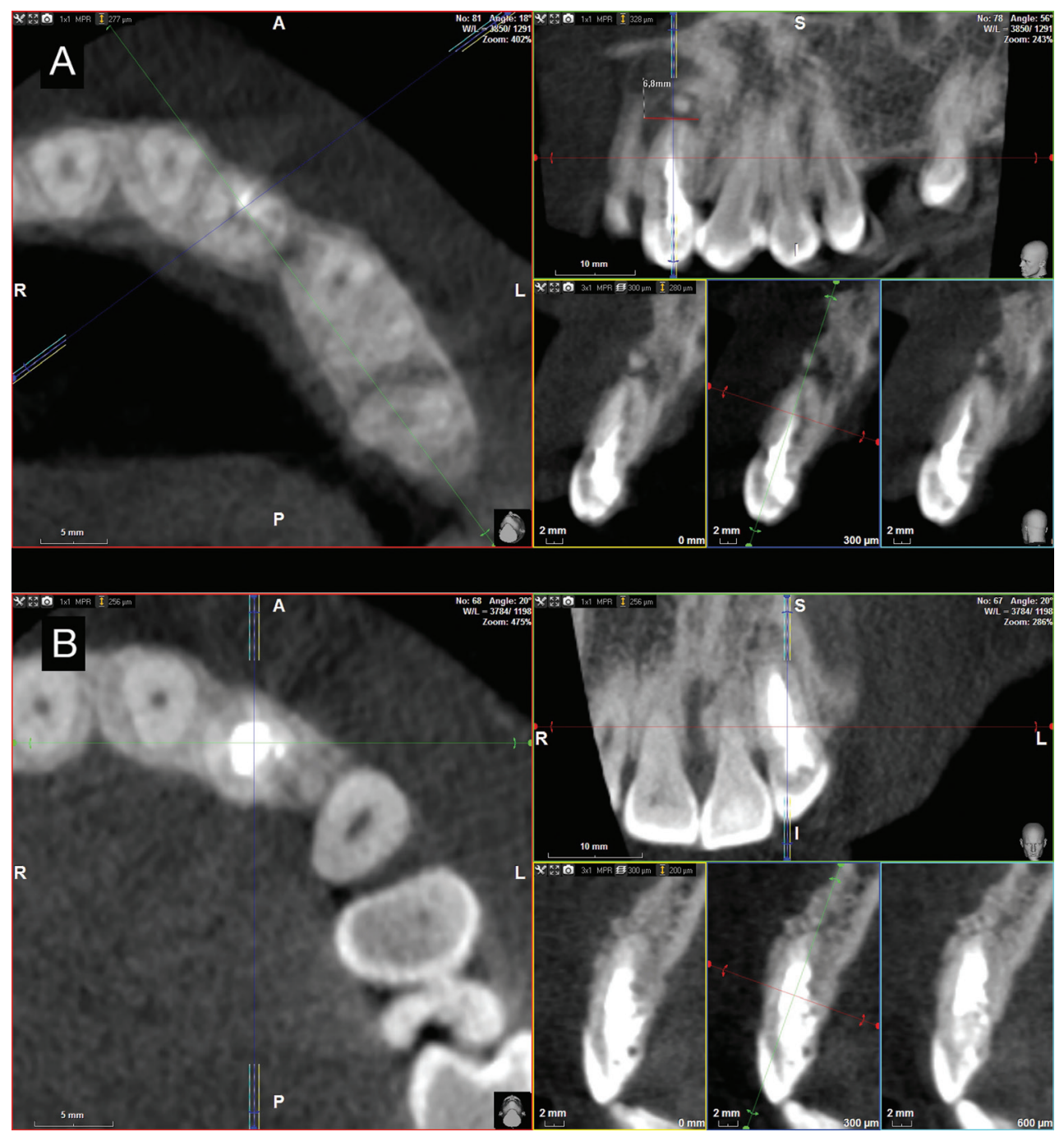

Fig. 2: Preoperative cone-beam computed cross-sections. Notice apical fracture and gutta-percha presence (A). Cone-beam computed tomography cross-sections follow-up at 18 months after treatment. Complete periradicular healing (B). 


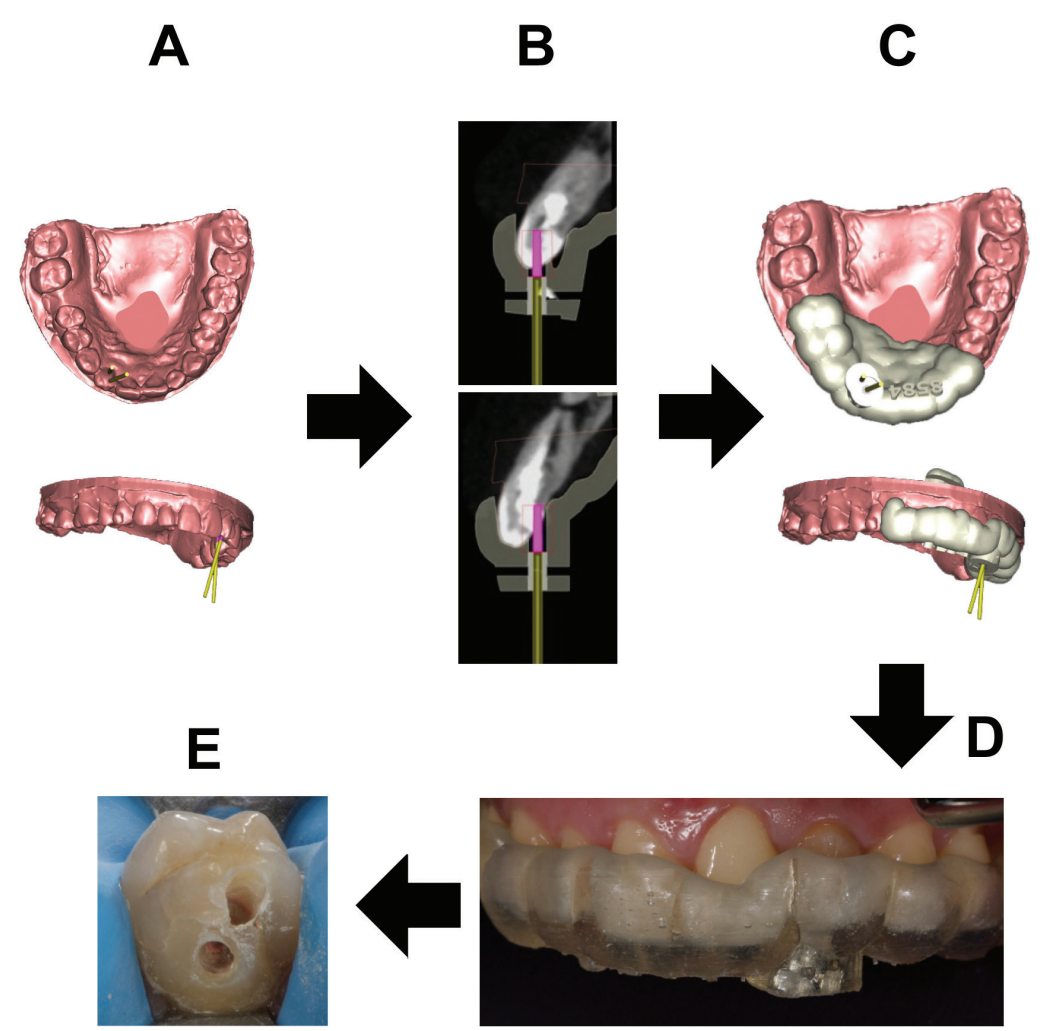

Fig. 3: Digital workflow to two access cavity (A-E).

working length was established by an electronic apex locator (Root ZX, Morita, Tokyo, Japan). The root canal system was cleaned and shaped with Reciproc ${ }^{\circledR}$ endodontic rotary system (R25, VDW ${ }^{\circledR}$, Munich, Germany). The root canal system was copiously irrigated with $5,25 \%$ sodium hypochlorite, and the contact between the irrigating solution and the surface of the root canal walls was enhanced by using an ultrasonic tip (IRRI S, VDW®, Munich, Germany) (21). After drying the root canal system with sterile paper points (Dentsply Maillefer, Ballaigues, Switzerland), the root canal system was sealed by employing a warm gutta-percha system (Calamus, Dentsply Maillefer, Ballaigues, Switzerland) and a epoxy resin-based cement (AH Plus, Dentsply DeTrey, Konstanz, Germany). The access cavities were filled with a composite restoration (Filtek Supreme XTE, 3MTM, MN, USA).

Then, the tooth was prepared for an indirect veneer, for improving the aesthetic. It was made with a digital worklow, from an impression made through an intraoral scanner (True Definition Scanner, 3M $\mathrm{M}^{\mathrm{TM}}$, MN, USA). The Stl file obtained, with this device, was sent over the internet, to a expertise dental technician, for designing the restoration through a CAD software (ExoCad, Darmstadt, Germany). Once the restoration was designed, it was sent to the dental clinic for manufacturing the indirect veneer with a block of resin nano- ceramic material (Lava $^{\mathrm{TM}}$ Ultimate A2 HT, 3M ${ }^{\mathrm{TM}}$, MN, USA) in a 4-axis milling unit (Roland®DG Iberia DWX-4, Hamamatsu, Japan). The restoration was cemented with a complete isolation with rubber dam, using a light-curing cement (RelyX'TM Veneer ${ }^{\mathrm{TM}}$ TR, MN, USA) (Fig. 4).

The endodontic surgery was carried out in order to remove the fractured apex. A modified Newman incision was made to remove the cystic tissue through the curettage of the bone defect. A $3 \mathrm{~mm}$ retrocavity was designed by means of a diamond ultrasonic tip (Ref.: PUSURG \#2, ProUltra ${ }^{\circledR}$, Dentsply Maillefer ${ }^{\circledR}$, Ballaigues, Switzerland). An haemostatic agent of aluminum chloride-based was used (Expacen $®$, Acteon $\AA$ Pierre Roland, Merignac, France) and the retrocavity preparation was sealed with mineral trioxide aggregate as root-end filling material (ProRoot ${ }^{\circledR}$ MTA white, Dentsply Tulsa Dental ${ }^{\circ}$, Tulsa, UK). Then, a bone graft was carried out (Bio-Oss ${ }^{\circledR}$, Geistlich Pharma North America Inc., Princeton, NJ, USA) and the incision was sutured with nylon 5/0 (Figure 5) (Seralene $\AA$, Serag-Weissner Iberia, Madrid, Spain) (Figure 1B). The patient was scheduled for follow-up appointments at 6,12 and 18 months in order to assess the evaluation of the treatment. At the 18 months follow-up visit, the patient remained asymptomatic and periapical radiograph (Fig. 1C) and CBCT scan (Fig. 2B) showed a reduction of the periapical lesion. The size of the periapical lesion was measured over the CBCT using the ruler tool of the WhiteFox software. Preoperative lesion (Fig. 2A) showed a 6,8 mm diameter 

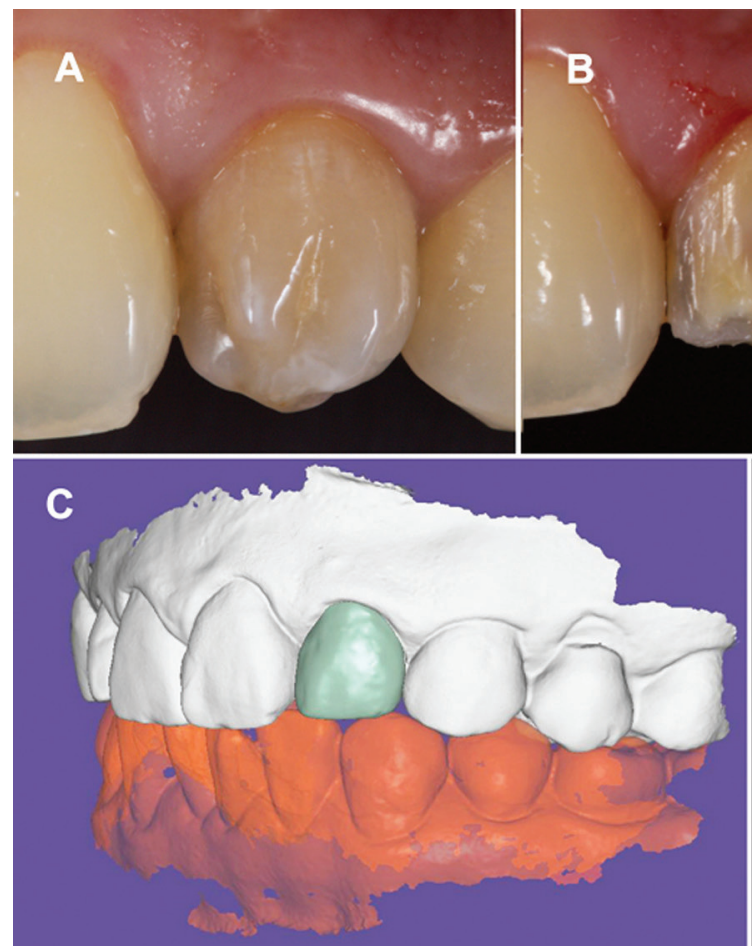

Fig. 4: Treatment planning sequence of CAD/CAM veneer (A-E)
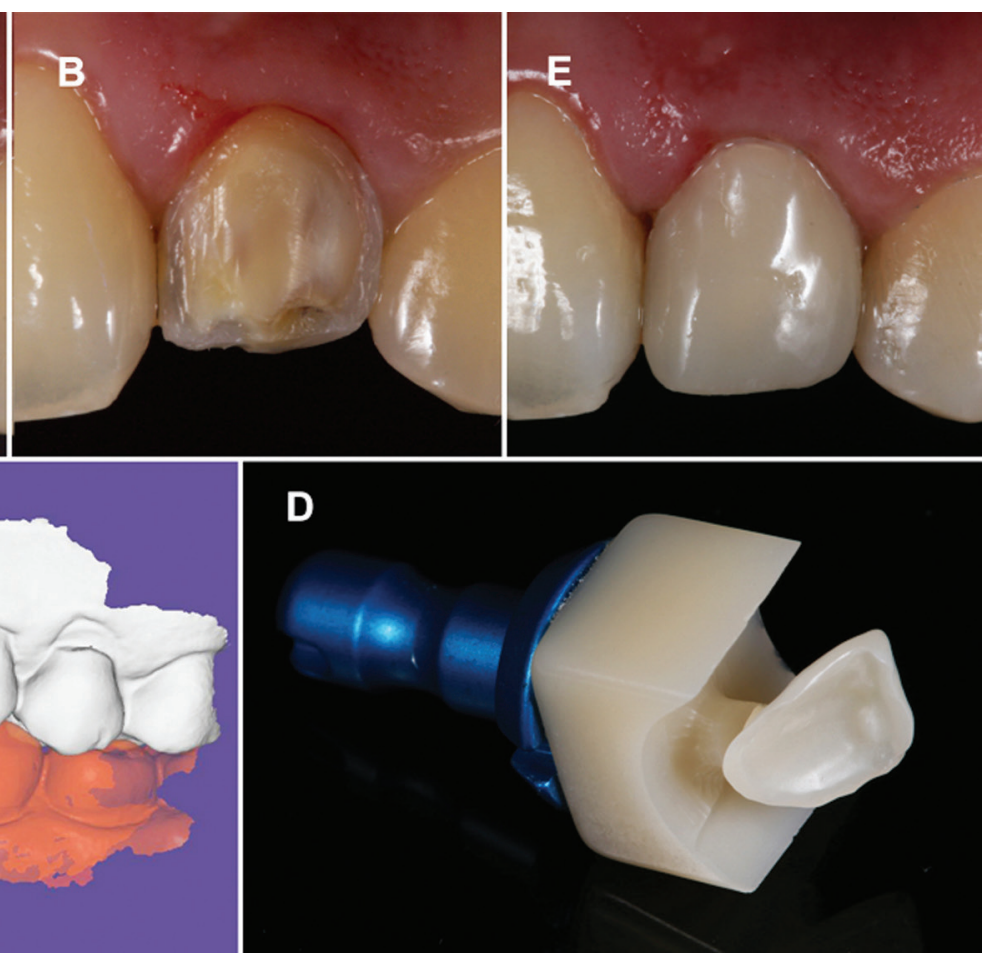

in its higher plane, which was disappeared at 18 months follow-up (Fig. 2B).

\section{Discussion}

Treatment planning of dental malformations is directly related to the anatomical complexity of each individual case. Many therapeutic strategies have been proposed to treat DI, depending on the previous diagnosis. Nevertheless, none focused attention on the access cavity complicating the restorative treatment procedure and weakening the coronal structure (19). The complex anatomy associated to this type of DI previously treated with fractured apex, required advanced therapeutic procedures which can be a challenge for the clinician. A straight line access to the root canal system is necessary to locate all canals, facilitate disinfection and complete debridement, as well as for avoiding loss of an excess of dental structure (20-22). One narrow single bur used to the access cavity implies a higher accuracy and a more conservative preparation than several burs of different shape. The guided access devices of computer-aided rapid prototyping were designed to apply them in implant guided surgery (23). However, their high versatility has pushed their application in endodontic field, enabling the location of the root canal systems affected by anatomical malformations (24) or calcific metamorphosis $(25,26)$, through guided and conservative access cavities. This CAD-CAM access devices show a mean deviation of $0,16 \mathrm{~mm}$ between the planned and performed access cavity at the tip of the bur $(22,23)$. These measures allowed an accurate, conservative and safe access cavity to the root canal system. The manufacturing process of the guided access devices may be carried out using two computer-aided rapid prototyping additive techniques: stereolithography or 3-dimensional digital printing. Nevertheless, the computer-aided rapid prototyping models obtained from 3-dimensional digital printing technology (ProJet ${ }^{\circledR}$ 6000. 3D Systems $\subset$, Rock Hill, SC, USA), show a degree of accuracy and fit higher to the models obtained from stereolithography technology (27), reducing the discrepancies noted at the access for implant guided surgery 23 and allowing the location of the root canals (22).

It was considered that the fractured apex should be removed because it was not possible to clean the root canal present inside, and could promote the persistence of the infectious process (19). CBCT imaging was used as radiographic method for the diagnosis, treatment planning and follow-up appointments, because it has showed a more accurate in identifying root canal system than periapical radiograph (9). This radiographic tool gives 3-dimensional digital images enabling to analyze root canal system, including the bone affected area with significatively less radiation exposure tan computed tomographic scans. This radiographic tool gives 3-dimensional digital images enabling to analyze bone healing process with significatively less radiation exposure tan computed tomographic scans (8). Therefore, it was used as adjunct of clinical examination to assess the treatment outcome in the follow-up appointments. 
For the final restorative treatment of the tooth a monolithic indirect veneer was obtained. A digital workflow was used in this case, by using an intraoral digital scanner and milling unit, avoiding to work with a physic model (28). We used in this case a chairside workflow, where the restoration is placed in one appointment. In our case, we use partial chairside system, where our restoration was designed by an expertise dental technician with a lab CAD software, with more options and applications than the CAD software of the devices of dental clinics, obtaining a more detailed design. Nevertheless, this workflow with sending the STL file to the dental technician, increase the treatment time with respect a total chairside system, where all steps are done in dental clinic.

These type of restorations obtained from a digital impression seem to have a similar o better results in several studies where the marginal of the restorations, were better to compare with a conventional workflow (29-31). Also in these type of cases, where a digital workflow with monolithic restorations, the result of clinical parameters such as points of contact, occlusion and the fit at clinical level are better than those restorations manufactured with a conventional workflow. In the clinical case presented, no adjustments had to be made in the areas of interproximal contact and the adjustment of the restoration was adequate, in accordance with the existing scientific literature.

\section{Conclusions}

CBCT is the most effective diagnostic method to know the internal anatomy of the teeth with anatomical malformations, and perform the radiographic follow-up. The computer-guided implant planning software is an effective way of planning the root canal treatment. The splints made by 3-dimensional digital printing allow us a accurate, conservative and safe cavity access from the teeth affected by anatomical malformations. The chairside systems allow us to realize precise and foreseeable restorations in a single clinical session.

\section{References}

1. Hülsmann M. Dens invaginatus: aetiology, classification, prevalence, diagnosis. And treatment considerations. Int Endod J. 1997;30:79-90.

2. Pradeep K, Charlie M, Kuttappa MA, Rao PK. Conservative management of type III dens in dente using cone beam computed tomography. J Clin Imaging Sci. 2012;2:51.

3. Demartis P, Dessí C, Cotti M, Cotti E. Endodontic treatment and hypotheses on an unusual case of dens invaginatus. J Endod. 2009;35:417-21.

4. Raut AW, Mantri V, Kala S, Raut RA. Management of "labial" type of dens invaginatus: A rare case report. J Oral Biol Craniofac Res. 2016;6:253-6.

5. Sathorn C, Parashos P. Contemporary treatment of class II dens invaginatus. Int Endod J. 2007;40:308-16.

6. Kfir A, Telishevsky-Strauss Y, Leitner A, Metzger Z. The diagnosis and conservative treatment of a complex type 3 dens invaginatus using cone beam computed tomography (CBCT) and 3D plastic models. Int Endod J. 2013;46:275-88.

7. Mupparapu M, Cantante SR, Goodchild JH. Dens evaginatus and dens invaginatus in a maxillary lateral incisor: report of a rare occurrence and review of literature. Aus Dent J. 2004;49:201-3.

8. Teixidó M, Abella F, Duran-Sindreu F, Moscoso S, Roig M. The use of cone-beam computed tomography in the preservation of pulp vitality in a maxillary canine with type 3 dens invaginatus and an associated periradicular lesion. J Endod. 2014;40:1501-4.

9. Matherne RP, Angelopoulos C, Kulild JC, Tira D. Use of cone-beam computed tomography to identify root canal systems in vitro. J Endod. 2008;34:87-9.

10. Roth JS. CBCT technology: endodontics and beyond, part 2. Dent Today. 2011;30:78, 80-3.

11. Lichota D, Lipski M, Wozniak K, Buczkowska-Radlińska J. Endodontic treatment of a maxillary canine with type 3 dens invaginatus and large periradicular lesion: a case report. J Endod. 2008;34:756-8. 12. Nallapati S. Clinical management of a maxillary lateral incisor with vital pulp and type 3 dens invaginatus: a case report. J Endod. 2004;30:726-31.

13. Ikeda H, Yoshioka T, Suda H. Importance of clinical examination and diagnosis: a case of dens invaginatus. Oral Surg Oral Med Oral Pathol Oral Radiol Endod. 1995;79:88-91.

14. Yang J, Zhao Y, Qin M, Ge L. Pulp revascularization of inmature dens invaginatus with periapical periodontitis. J Endod. 2013;39:28892.

15. Narayana P, Hartwell GR, Wallace R, Nair UP. Endodontic clinical management of a dens invaginatus case by using a unique treatment approach: a case report. J Endod. 2012;38:1145-8.

16. Kumar H, Al-Ali M, Parashos P, Manton DJ. Management of 2 teeth diagnosed with dens invaginatus with regenerative endodontics and apexification in the same patient; a case report and review. J Endod. 2014;40:725-31.

17. Štamfelj Ĭ, Kansky AA, Gašperšič D. Unusual variant of type 3 dens invaginatus in a maxillary canine: a rare case report. J Endod. 2007;33:64-8.

18. Wölner-Hanssen AB, von Arx T. Permanent teeth with horizontal root fractures after dental trauma. A retrospective study. Schweiz Monatsschr Zahnmed. 2010;120:200-12.

19. Zoya A, Ali S, Alam S, Tewari RK, Mishra SK, Kumar A. Double dens invaginatus with multiple canals in a maxillary central incisor: Retreatment and managing complications. J Endod. 2015;41:1927-32. 20. Levin LG, Law AS, Holland GR, Abbott PV, Roda RS. Identify and define all diagnostic terms for pulpal health and disease states. $\mathrm{J}$ Endod. 2009;35:1645-57.

21. Rico-Romano C, Zubizarreta-Macho Á, Baquero-Artigao MR, Mena-Álvarez J. An analysis in vivo of intracanal bacterial load before and after chemo-mechanical preparation: A comparative analysis of two irrigants and two activation techniques. J Clin Exp Dent. 2016;8:e9-e13.

22. Zender MS, Connert T, Weiger R, Krastl G, Kühl S. Guided endodontics: accuracy of a novel method for guided access cavity preparation and root canal location. Int Endod J. 2016;49:966-72.

23. Van Assche N, Vercruyssen M, Coucke W, Teughels W, Jacobs R, Quirynen M. Accuracy of computer-aided implant placement. Clin Oral Implants Res. 2012;23:112-23.

24. Zubizarreta-Macho A, Ferreiroa A, Rico-Romano C, Alonso-Ezpeleta LÓ, Mena-Álvarez J. Diagnosis and endodontic treatment of type II dens invaginatus by using cone-beam computed tomography and splint guides for cavity access: a case report. J Am Dent Assoc. 2015;146:266-70.

25. Buchgreitz J, Buchgreitz M, Mortensen D, Bjørndal L. Guided access cavity preparation using cone-beam computed tomography and optical surface scans-an ex vivo study. Int Endod J. 2016;49:790-5.

26. Van der Meer WJ, Vissink A, Ng YL, Gulabivala K. 3D computer aided treatment planning in endodontics. J Dent. 2016;45:67-72.

27. Una Reyes, Turkyilmaz I, Prihoda TJ. Accuracy of surgical guides made from conventional and a combination of digital scanning and rapid prototyping techniques. J Prosthet Dent. 2015;113:295-303.

28. Bosch G, Ender A, Mehl A. A 3-dimensional accuracy analysis of chairside CAD/CAM milling processes. J Prosthet Dent. 2014;112:1425-31. 
29. Pradíes G, Zarauz C, Valverde A, Ferreiroa A, Martínez-Rus F. Clinical evaluation comparing the fit of all-ceramic crowns obtained from silicone and digital intraoral impressions based on wavefront sampling technology. J Dent. 2015;43:201-8.

30. Berrendero S, Salido MP, Valverde A, Ferreiroa A, Pradíes G. Influence of conventional and digital intraoral impressions on the fit of CAD/CAM-fabricated all-ceramic crowns. Clin Oral Investig. 2016;20:2403-10

31. Berrendero S, Salido MP, Ferreiroa A, Valverde A, Pradíes G. Comparative study of all-ceramic crowns obtained from conventional and digital impressions: clinical findings. Clin Oral Investig. 2019;23:1745-51.

Acknowledgment

The authors would like to thank Santiago López Martínez, Marina Monjo Calderón, Eduardo García Arocena, Alfonso García Hernández, Manuel Fariña and Z-tech Digital Dental Group their invaluable assistance in this case report.

\section{Conflict of interest}

The authors have declared that no conflict of interest exist. 